\title{
Application of the Theory of Planned Behavior in Dietary and Physical Activity Behaviors among Hemodialysis Patients Visiting Army Hospitals
}

\section{Banafsheh Dormanesh (PhD) ${ }^{1}$, Reza Daryabeigi (MSc) ${ }^{2, *}$, Saeid Hadi (MSc) ${ }^{2}$, Vahid Sepahvand $(\mathrm{BSc})^{3}$, Alireza Sarkhosh Tonekaboni $(\mathrm{BSc})^{4}$}

${ }^{I}$ Associate Professor, AJA University of Medical Sciences, Tehran, Iran

${ }^{2}$ AJA University of Medical Sciences, Tehran, Iran

${ }^{3}$ Emam Reza Hospital, Tehran, Iran

${ }^{4}$ Air Force Besat Hospital, Tehran, Iran

* Corresponding Author: Reza Daryabeigi, AJA University of Medical Sciences, Tehran, Iran. Email: rezadaryab3@yahoo.com

Abstract

Received: $22 / 12 / 2016$

Accepted: 28/01/2018

\section{How to Cite this Article:} Dormanesh B, Daryabeigi R, Hadi S, Sepahvand V, Sarkhosh Tonekaboni A. Application of the Theory of Planned Behavior in Dietary and Physical Activity Behaviors among Hemodialysis Patients Visiting Army Hospitals. Pajouhan Scientific Journal. 2018; 16(2): 19-27. DOI: $10.21859 / \mathrm{psj} .16 .2 .19$
Background and Objective: Dietary behaviors and physical activity are critical in the prevention of cardiovascular disease and reducing mortality among hemodialysis patients. The predictive ability of the theory of planned behavior (TPB) in relation to dietary (sodium and potassium) and physical activity behaviors was assessed among end-stage renal disease (ESRD) patients undergoing hemodialysis at hospitals affiliated with the Iranian Army.

Materials and Methods: A cross-sectional study was conducted among 62 ESRD patients who were undergoing hemodialysis. TPB questionnaires were completed via a face-to-face interview by trained researchers a week prior to the behavior assessment. Self-reported behaviors were then assessed during the weekend. Moreover, dietary sodium and potassium intakes were evaluated using 24-hour dietary recall and further analyzed with Nutritionist 4 software. Hierarchical Multiple Regression (HMR) analyses were performed using SPSS (version 18: IBM corporation).

Results: Findings showed that the TPB explains $26.5 \%$ (22.6\% adjusted), ( $\mathrm{P} \leq 0.01), 25.7 \%$ (18.1\% adjusted), $(\mathrm{P} \leq 0.01)$ and $33.6 \%$ (30.0\% adjusted), $(\mathrm{P} \leq 0.01)$ of the changes in self-reported sodium restriction, potassium restriction and physical activity performance, respectively. Furthermore, TPB predicted $28.5 \%(21.8 \%$ adjusted $),(\mathrm{P} \leq 0.01)$ and $25.6 \%(19.3 \%$ adjusted $),(P \leq 0.01)$ of the variances in the dietary intakes of sodium and potassium.

Conclusion: The present study reveals valuable findings in support of applying TPB in hemodialysis patients and paves the way for effective future educational interventions.

Keywords: Behavior; Dietary Potassium; Dietary Sodium; Hemodialysis; Physical Activity 
بررسى كاربرد تئورى رفتار برنامهريزى شده در رفتارهاى تغذيهاى و فعاليت فيزيكى

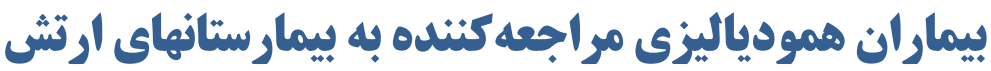

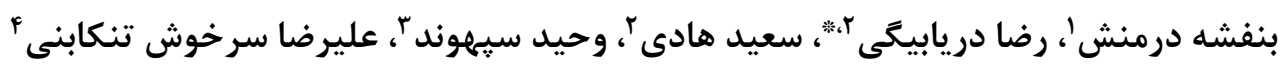

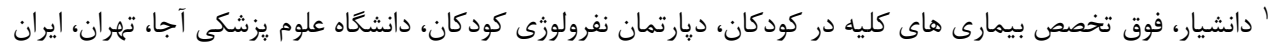

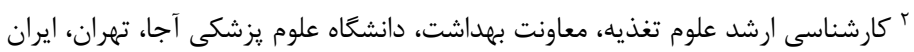

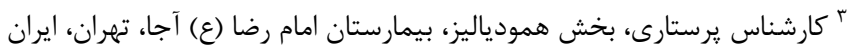

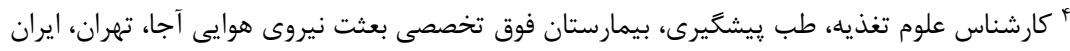
* نويسنده مسئول: رضا دريابيكى، معاونت بهداشت، دانشكاه علوم يزشكى آجا، تهران، ايران. ايميل: rezadaryab3@yahoo.com

\begin{tabular}{|c|c|}
\hline جكيده & \\
\hline سابقه و هدف: براى ييش كيرى از بيمارىهاى قلبى- عروقى و كاهش مركى و مير در بيماران & 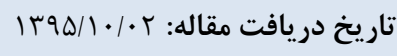 \\
\hline همودياليزى، رفتارهاى تغذيهاى و فعاليت فيزيكى مهمم هستند. مطالعه حاضر با هدف تعيين قابليت & 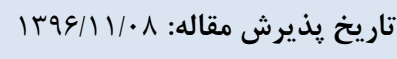 \\
\hline تئورى رفتار برنامه ريزى شده (TPB) در يِيشبينى رفتارهاى تغذيهاى (محدوديت سديمم و يتاسيم) و & \\
\hline فيمارستانهاي فيكى در آجام شدان بيماران مرحله نهايى كليوى (ESRD) تحت همودياليز مراجعه كننده به & يزشكى همدان محفوظ است. \\
\hline مواد و روشها: مطالعهى مقطعى بر روى rو بيمار ESRD تحت همودياليز انجام يذيرفت. يك هفته & \\
\hline قبل از سنجش رفتار، بيماران يرسشنامه هاى TPB , در قالب مصاحبه جهره به جهره توسط افراد & \\
\hline آموزش ديده تكميل كردند. رفتار خودكزارش دهى در انتهاى هفته سنجيده شد. همجنين دريافت غذايى & \\
\hline Nutritionist 4 سديم و يتاسيم با يادآمد غذايى YF ساعته در انتهاى هفته اندازه كيرى و با نرم افزار & \\
\hline آناليز شد. تحليل آمارى ركرسيون سلسله مراتبى (HMR) با نرم افزار SPSS (نسخه IN) صورت & \\
\hline يذيرفت. & \\
\hline يافته ها: مدل TPB توانست به ترتيب & \\
\hline 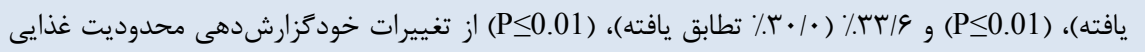 & \\
\hline 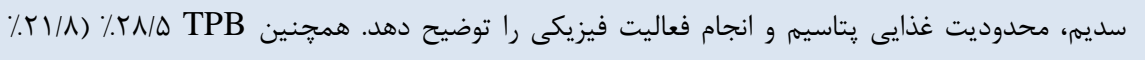 & \\
\hline 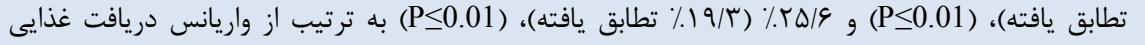 & \\
\hline 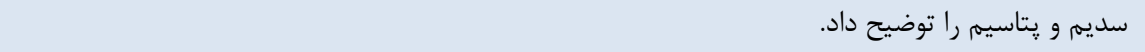 & \\
\hline نتيجهَيرى: يافتههاى مطالعه حاضر نتايج ارزشمندى در حمايت از كاربرد تئورى رفتار برنامه ريزى شده در & \\
\hline بيماران همودياليزى ارائه مىدهد و زمينه انجام مداخلات آموزشى اثربخش را در آينده هموار مى كند. & \\
\hline وازَّان كليدى: يتاسيم غذايى؛ سديم غذايى؛ رفتار؛ فعاليت فيزيكى؛ همودياليز & \\
\hline
\end{tabular}

ديابت و هاييرتانسيون عوامل خطر اصلى ESRD مىباشند

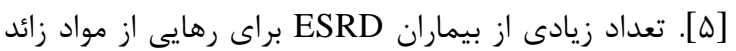

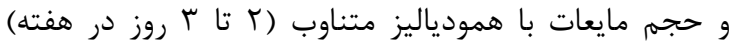

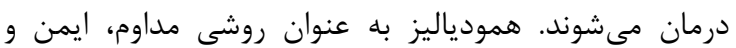

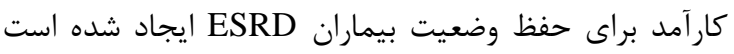

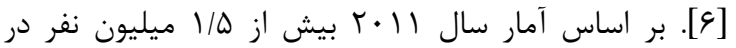

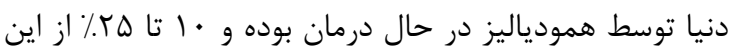

بيمارى مرحله نهايى كليوى End-stage renal disease زمانى اتفاق مىافتد كه كليهها ديكر كفايت لازم براى (ESRD)

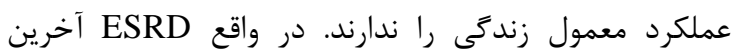

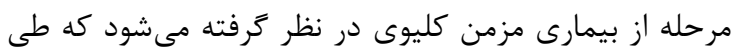

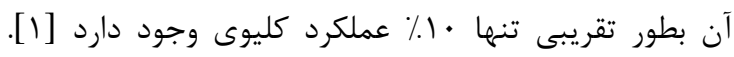

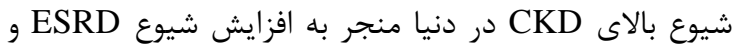

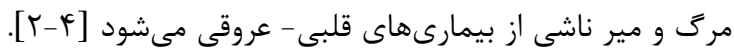


علاوه باورهاى مههم كه هدف مداخله آموزشى قرار مى گيرند بايد

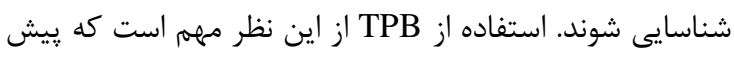

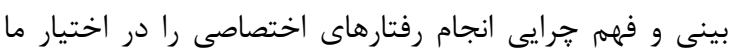

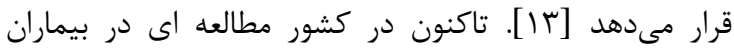

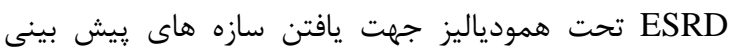

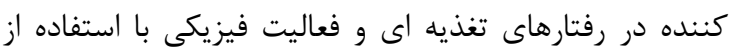

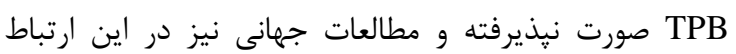

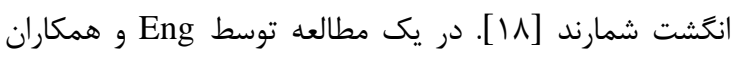

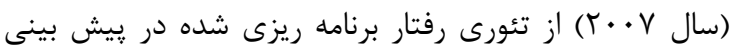

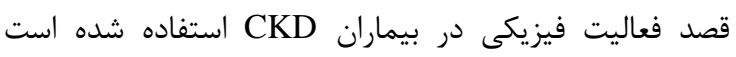
[19] [19. بعنوان متغير معنى دار در ييش بينى قصد بيماران

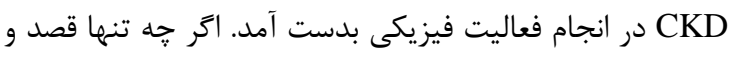

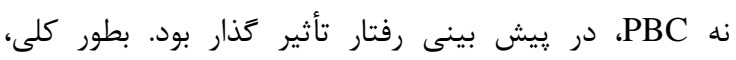

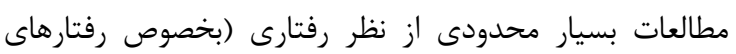

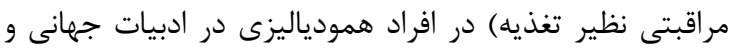
ملى وجود دارد. با توجه به كمبود مطالعات در زمينه TPB و رود رفتارهاى

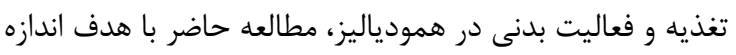

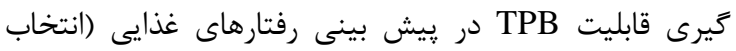
غذاى كم سديم و انتخاب غذاى كم يتاسيم) و فعاليت فيزيكى دئي

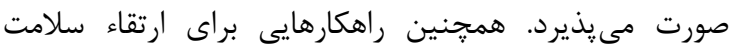

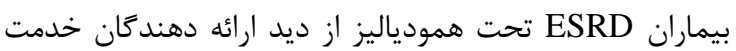

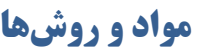

مطالعهاى مقطعى جهت ارزيابى TPB در پيش رولى بيشى

رفتارهاى غذايى و فعاليت فيزيكى بيماران ESRD تحت

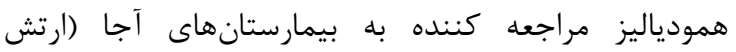

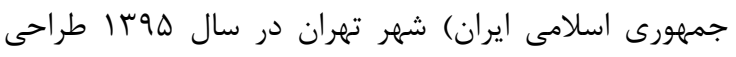

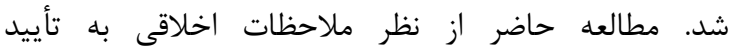

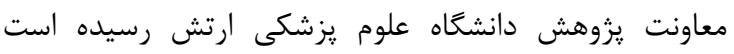

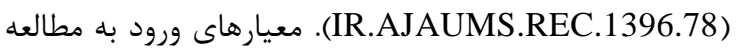

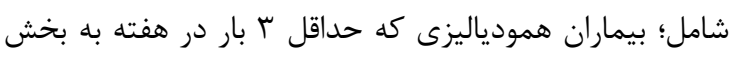

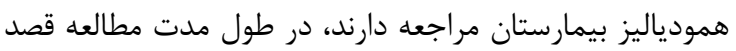

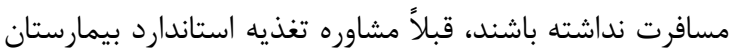

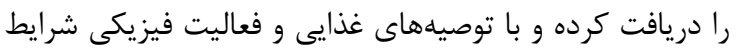

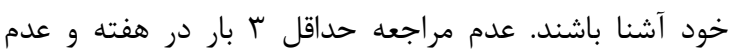
دريافت مشاوره استاندارد تغذيه بيمارستان نيز معيارهاى خرائ خروج

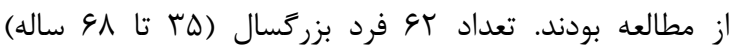
همودياليزى مراجعه كننده وارد مطالعه شدند. بدليل محدوديت برديت

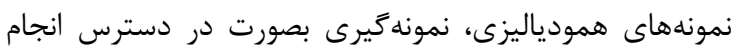

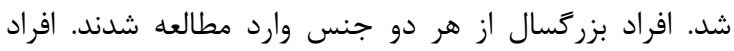

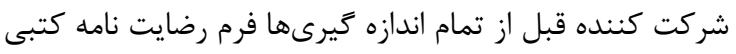

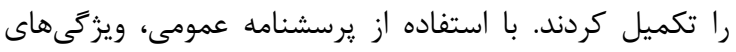

افراد هر ساله جان خود را از دست مى دهند [V]].

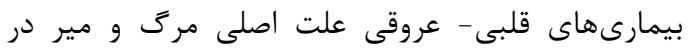
بيماران ESRD تحت همودياليز است. فشار خون به عله عنوان

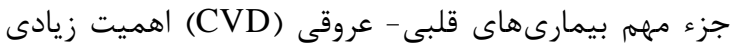

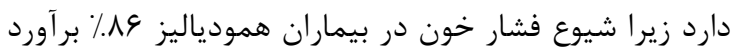

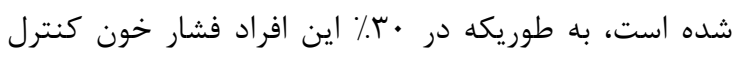

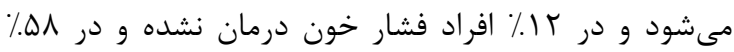

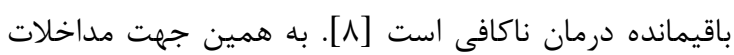

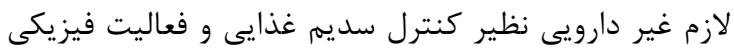

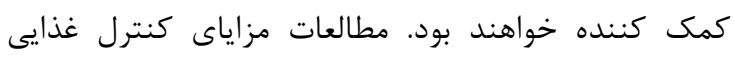

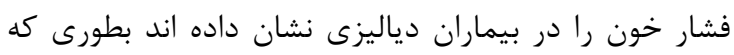

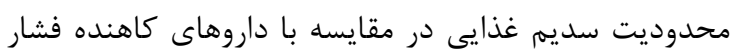

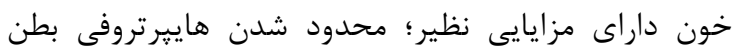

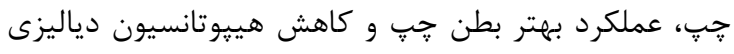

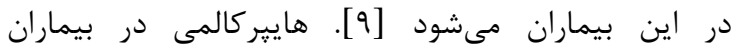

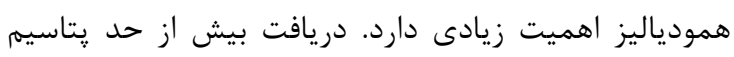

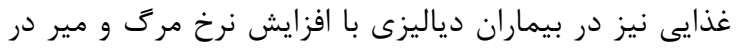

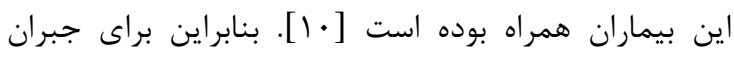

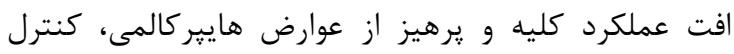

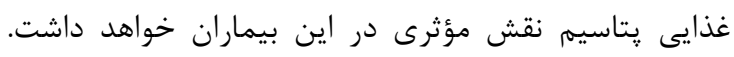

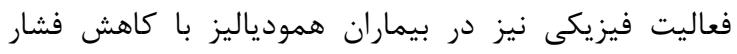

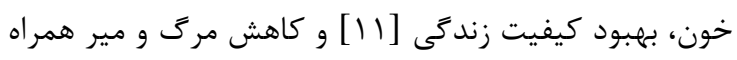

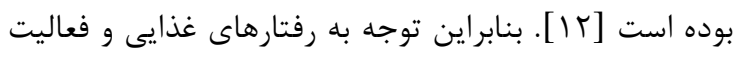

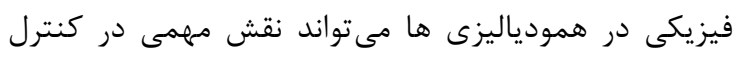

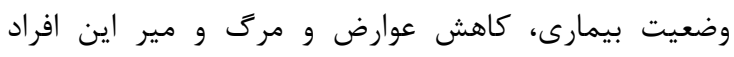
داشته باشد.

يكى از تئورىهاى آموزشى كه بر قصد رفتارى بنا نهاده

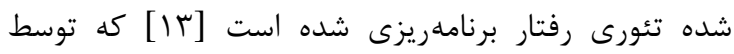
Ajzen

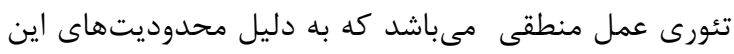

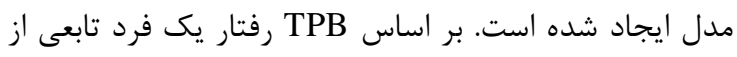

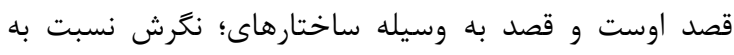

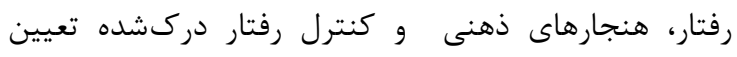

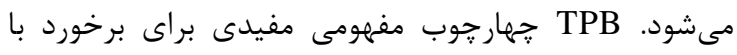

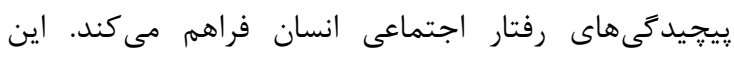

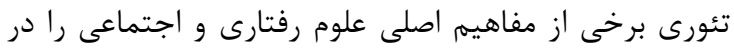

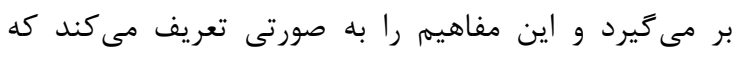

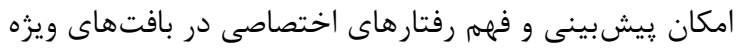

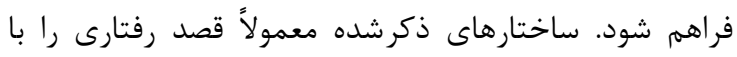

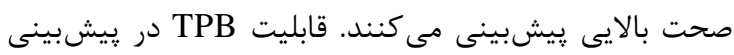

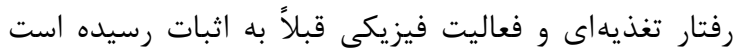

. [I $F-I V]$

قبل از انجام مداخلات رفتارى نياز است تا قابليت بيش

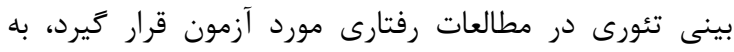


بررسى و بازخورد لازم را ارائه دهند. علاوه بر اين از تعداد

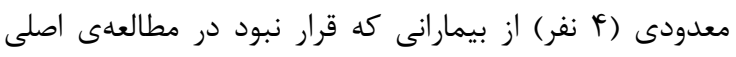

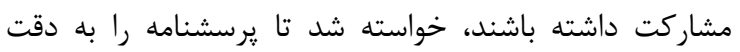

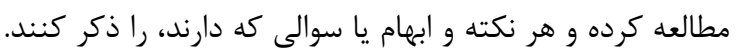

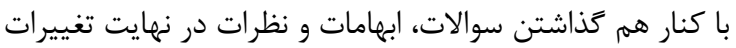

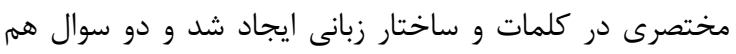
در اين ارتباط حذف كرديد و در نهايت ابزار اصلى تهيه شدان

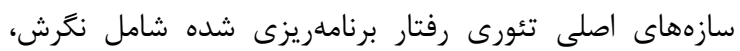

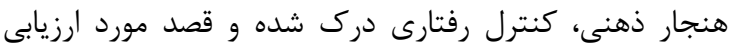

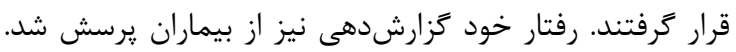

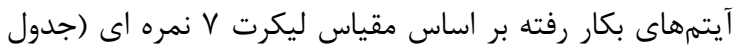

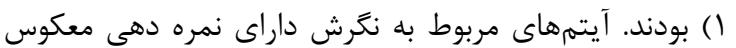

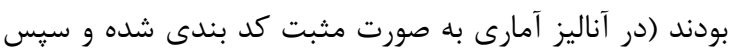

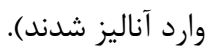

متغيرهاى وابسته، رفتارهاى خودَزارشدهنى غذايى (سديم

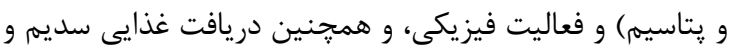

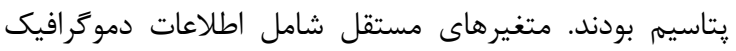
(عوامل زمينهاى)، رفتار كذشته و سازه هاى استاندارد TPB
دمو كرافيك شامل سن، جنس، شغل و سطح سواد، و همجنين

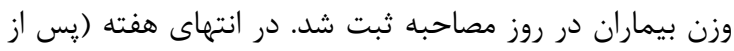

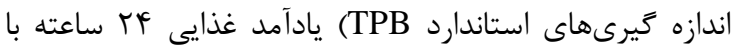

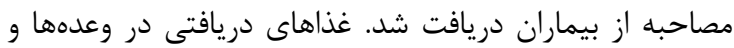

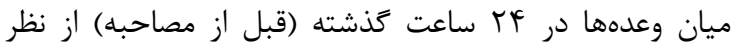

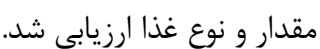
در ارتباط با رفتارهاى تغذيه الى و فعاليت إنايت فيزيكى،

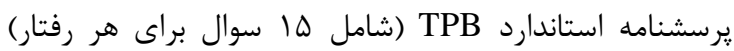

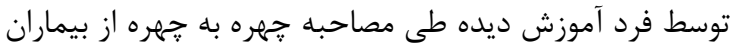

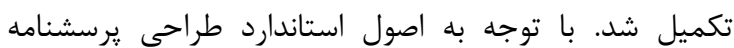

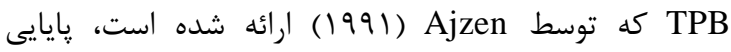

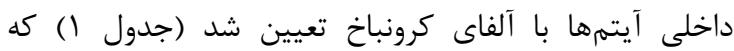

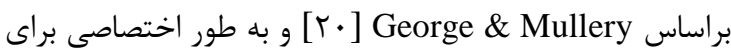

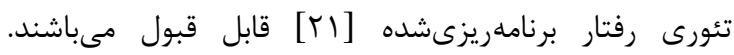

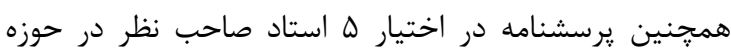

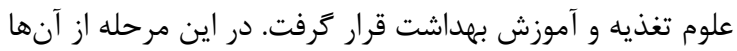

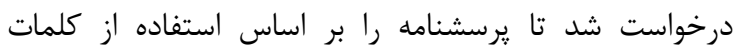
مناسب، قرارگيرى موارد در جاى مناسب و رعايت دستور زبان

جدول (: تعداد آيتمها، توافق درونى (آلفاى كرونباخ/همبستخى پِيرسون)، دسته بندى پاسخ، و اندازه گيرىهاى مستقيم تئورى رفتار برنامه ريزى شده

\begin{tabular}{|c|c|c|c|c|c|c|}
\hline 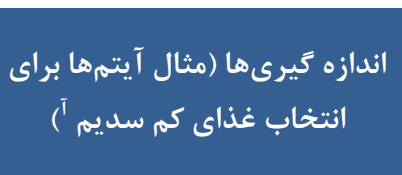 & دسته بندى آيتمها & فيز فعاليت & كريب همبساب غذاسك & آنتخاب غذاى & آيتمهـا & سازه \\
\hline 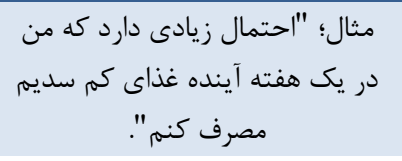 & ( & $\cdot . \wedge 1$ & $\cdot \vee \vee q$ & $\cdot V \Delta$ & $r$ & قصد \\
\hline 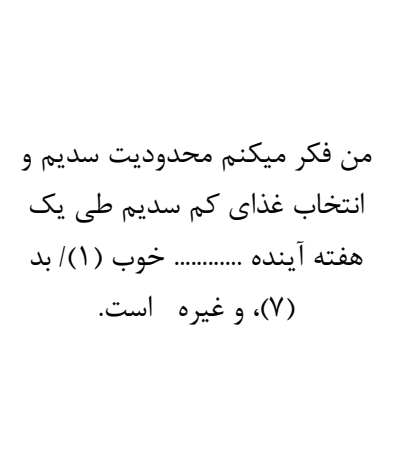 & 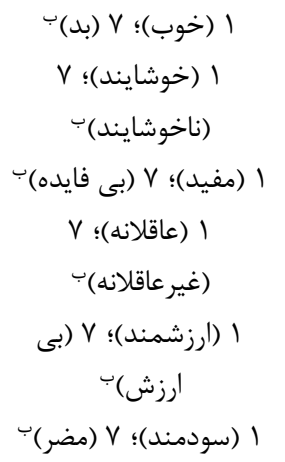 & $\cdot . \wedge r$ & $\cdot .91$ & $\cdot . \wedge \vee$ & 4 & نكرش \\
\hline 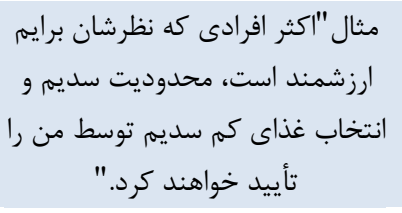 & ( 1 (كاملاً مخالفم)؛ Vوافقم) & •.94 & $\cdot .9 r$ & $\cdot .99$ & $r$ & هنجار ذهنى \\
\hline مصرف كنمم يا خير، به طور كامل به به مديه & I (كاملاً مخالفم)؛ V & $\cdot 9$. & $\cdot \vee \vee q$ & $\cdot . \wedge F$ & $r$ & كنترل رفتار \\
\hline 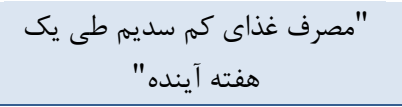 & 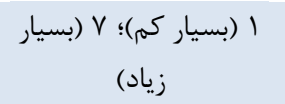 & - & - & - & 1 & رفتار \\
\hline
\end{tabular}

آ. تعداد آيتمها و مثالهاى مشابهى براى انتخاب غذاى كم بتاسيم و فعاليت فيزيكى وجود دارد. ب. آيتمهاى داراى نمره معكوس. 


\begin{tabular}{|c|c|c|}
\hline \multicolumn{2}{|c|}{ تعداد كل: Yو نفر } & \multirow{2}{*}{ متغير } \\
\hline درصد & تعداد & \\
\hline & & جنس \\
\hline$\Delta F / \wedge$ & mF & مونث \\
\hline \multirow[t]{2}{*}{$r \Delta / t$} & rA & مذكر \\
\hline & & سن \\
\hline $11 / 0$ & v & $r \cdot \geq$ \\
\hline$r F / F$ & rI & $\Delta \cdot|F|$ \\
\hline \multirow[t]{2}{*}{$\Delta F / 1$} & זr & $\omega \cdot \leq$ \\
\hline & & سطح تحصيلات \\
\hline$\varphi / \wedge$ & f & بى سواد \\
\hline$\Delta F / r$ & rT & ابتدايى و راهنمايى \\
\hline$r \cdot / r$ & ir & دبيرستان و دييلم \\
\hline \multirow[t]{2}{*}{$11 / 9$} & 11 & دانشَاهى \\
\hline & & وضعيت شغل \\
\hline$\Lambda / F$ & $\Delta$ & بيكار \\
\hline $10 / \mu$ & 9 & تمام وقت \\
\hline IV & $1 \cdot$ & ياره وقت \\
\hline$r T / r$ & 19 & بازنشسته \\
\hline$r V / I$ & 19 & خانه دار \\
\hline & & وضعيت تأهل \\
\hline$q V / T$ & rq & متأهل \\
\hline$r / \Delta$ & r & مجرد \\
\hline $9 / 9$ & r & مطلقه \\
\hline$T r / F$ & ir & همسر فوت شده \\
\hline
\end{tabular}

متغيرهاى استاندارد TPB در كام دوم وارد مدل شدند.

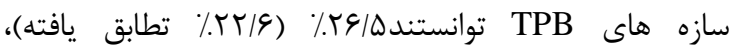

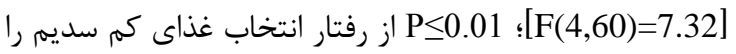
ييش بينى كنند. در نهايت قصد و PBC بطور معنىدارى

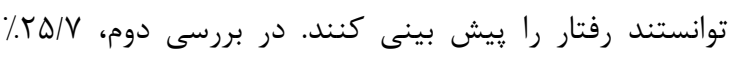

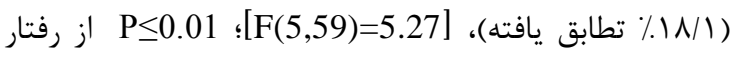

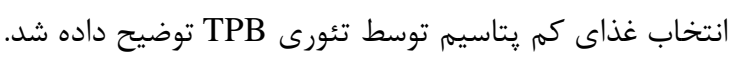
براى غذاى كمم يتاسيم در مدل نهايى رفتار كذشته، قصد PBC

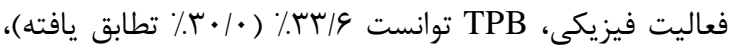

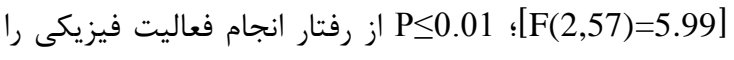
يیش بينى كند، كه در اين مدل رفتار كذشته، قصد و هنجار ذهنى بطور معنى دارى در توضيح رفتار مشاركت داشتند.

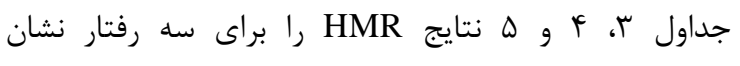

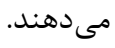
در فاز ثانويه آناليز، قابليت TPB در پيش بينى دريافت غذايى سديم و ريتاسيم مورد سنجش قرار كرفت. ميانگين

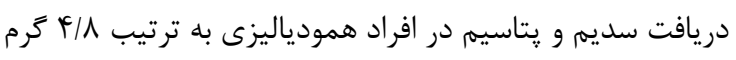

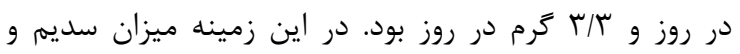

بودند. جدول ا سازههاى مطالعه، تعداد آيتمها، توافق درونى،

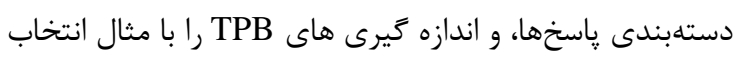
غذاى كم سديم نشان مى دهد. تعاريف رفتارهاى مورد نظر

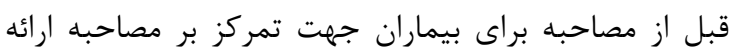

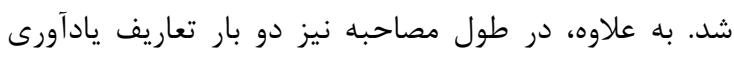

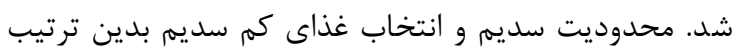

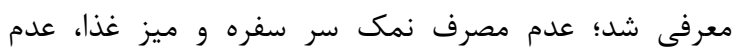

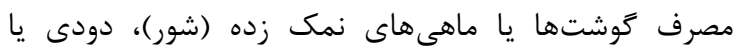
فرآورى شده، عدم مصرف ينير (به استثناء ينير خامه ایى) و و

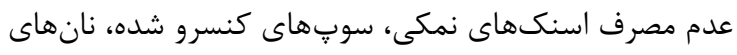

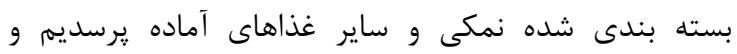

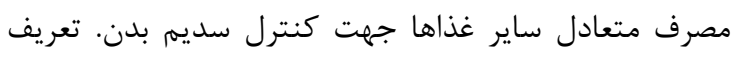

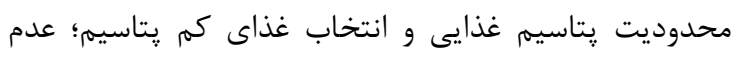
مصرف غذاهاى ير يتاسيم شامل ميوه ها (زردآلو، موز، انجير،

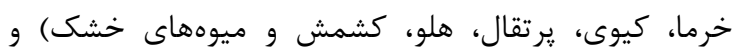

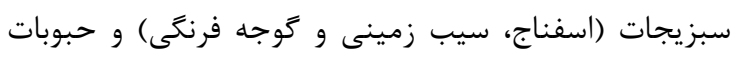

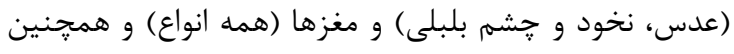

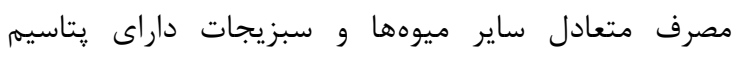
متوسط تا كم (سيب، كلابى، توت فرنكى، نارنكى كاهو، كلم،

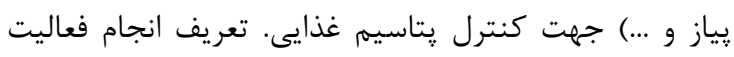

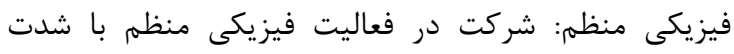

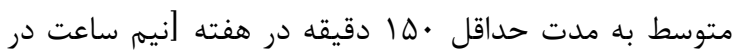
روز و در اكثر روزهاى هفته].

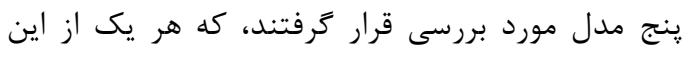

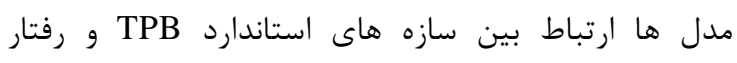

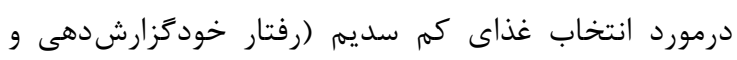

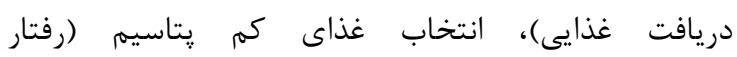
خودززارشدهى و دريافت غذايى) و انجام فعاليت فيزيكى (رئى

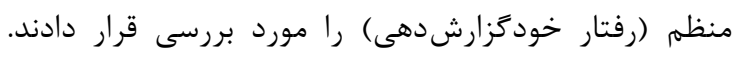

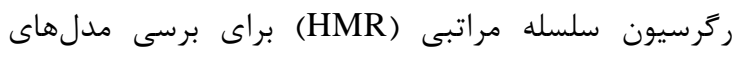

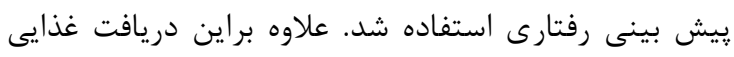

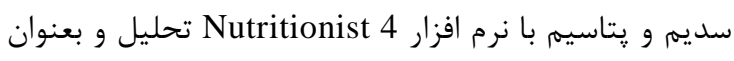

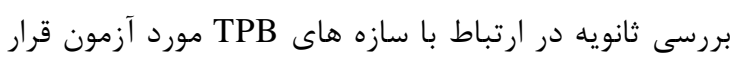

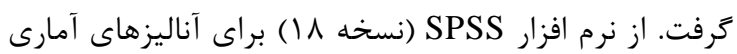

استفاده شد.

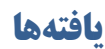

ويثز هاى هاى دموَرافيك افراد وارد شده به مطالعه در جدول

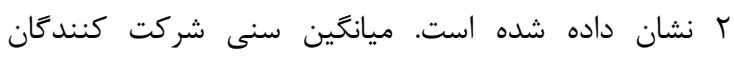

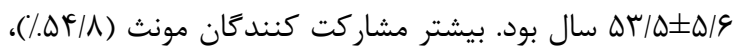

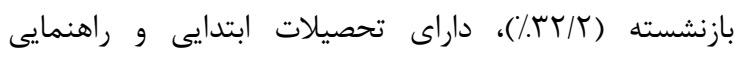
(بازن

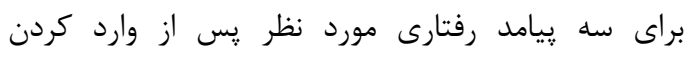

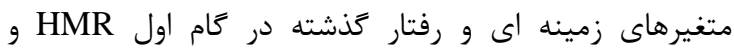




\begin{tabular}{|c|c|c|c|c|}
\hline$\beta$ & SE B & $\mathbf{B}$ & ميانگين & متغير \\
\hline & & & & مرحله اول \\
\hline \multirow[t]{2}{*}{$\cdot . r \cdot 1$} & $\cdot \cdot \wedge \vee$ & $\cdot .1 \vee 9$ & f.ru & رفتار كذشته" \\
\hline & & & & مرحله دوم \\
\hline$\cdot .|0|$ & $\cdot . \wedge 1$ &. $.1 T \Delta$ & F.MF & رفتار كذشته \\
\hline$\cdot \cdots \Delta$ &. $.19 r$ & $\cdot . \cdot 1 r$ & 9.11 & ن \\
\hline$\cdot \cdot \Delta V$ &. .111 &. .94 & D.rT & هنجار ذهنى \\
\hline$\cdot . r \Lambda F$ &. .148 & 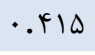 & 0.14 & كنترل رفتار درك شده"* \\
\hline$\cdot$.TG. & $\cdot .149$ & $\cdot r \Delta V$ & $\Delta . V V$ & قصد" \\
\hline
\end{tabular}

متغير وابسته: رفتار انتخاب غذاى كم سديم در انتهاى هفته. p p

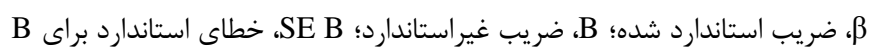
$\cdot, \Delta \geq$ • $\cdot$ : •, 1 :

جدول F) خلاصه آناليز ركرسيون سلسله اى براى متغيرهاى ييش بينى كننده رفتار انخاب غذاى كم يتاسيمم

\begin{tabular}{|c|c|c|c|c|}
\hline $\boldsymbol{\beta}$ & SE B & B & ميانكين & متغير \\
\hline & & & & مرحله اول \\
\hline \multirow[t]{2}{*}{$\cdot r \Delta}$. & $\cdot .111$ & $\cdot . r \Lambda F$ & r.ی1 & رفتار كذشته" \\
\hline & & & & مرحله دوم \\
\hline$. r \mid r$ & $\cdot .1 \cdot 9$ &. TY. & r.A1 & رفتار كذشته" \\
\hline$\cdot .+\uparrow \wedge$ & D & $\cdot .111$ & 9.rr & ن ن تخرش \\
\hline$\cdot . \Delta V$ & ת & $\cdot \cdot . V \mu$ & Q.rT & هنجار ذهنى \\
\hline. . TYV & ـ & - & $\Delta . r \Delta$ & كنترل رفتار درك شده" \\
\hline$\cdot . r \wedge 9$ &. $.1 F V$ & $\cdot r \cdot \Lambda$ & 0.9. & قصد \\
\hline
\end{tabular}

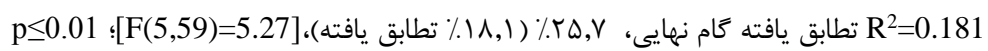

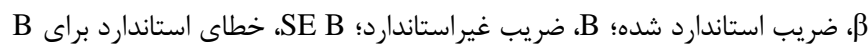

$\cdot, \Delta \geq$ • $\cdot$ :

•,

جدول ه: خلاصه آناليز ركرسيون سلسله اى براى متغيرهاى بيش بينى كننده رفتار فعاليت فيزيكى منظم

\begin{tabular}{|c|c|c|c|c|}
\hline $\boldsymbol{\beta}$ & SE B & B & ميانكين & متغير \\
\hline & & & & مرحله اول \\
\hline \multirow[t]{2}{*}{$\cdot \cdot r \cdot r$} & $\cdot .1 \cdot r$ & $\cdot .4 F q$ & ५.^८ & رفتار كذشته \\
\hline & & & & مرحله دوم \\
\hline. TYI & $\cdot .1 \cdot r$ & $\cdot . r \& \Lambda$ & ५.^८ & رفتار كذشته" \\
\hline$\cdot . \Delta 9$ & $\cdot r \Delta \varphi$ &..$I V F$ & 9.94 & نكَرش \\
\hline ש &..$|Y|$ & $\cdot . r V V$ & $0.4 q$ & هنجار ذهنى "**" \\
\hline. .991 &. .110 & $\cdot . \cdot \vee \wedge$ & 4.99 & كنترل رفتار درى شده \\
\hline . TKG & $\cdot 10$ & · r MA & 0.1 . & قصد" \\
\hline
\end{tabular}

متغير وابسته: رفتار انتهاى هفته.

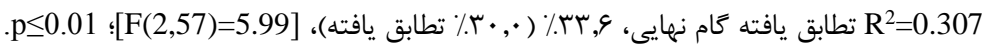

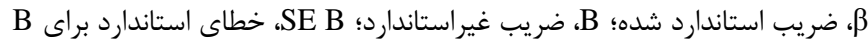

*.سطح معنى دارى

. 
مى توان جنين توضيح داد كه بيماران همودياليزى كنترل

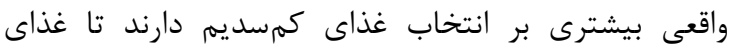

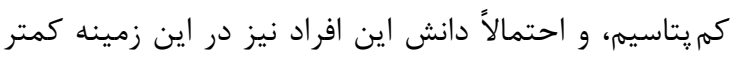

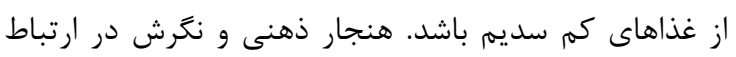

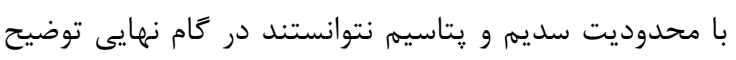

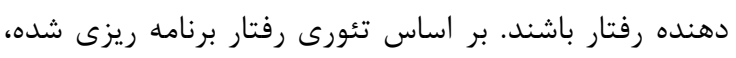

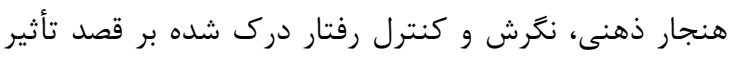

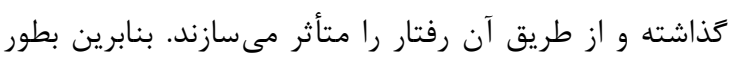

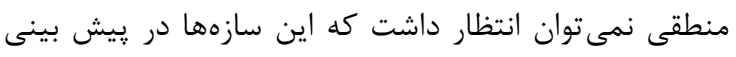

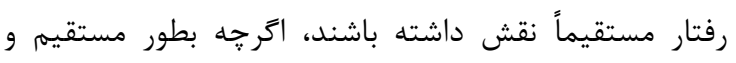

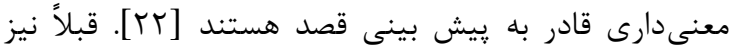

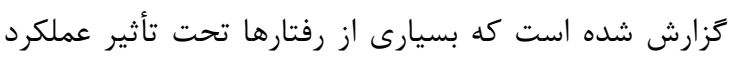

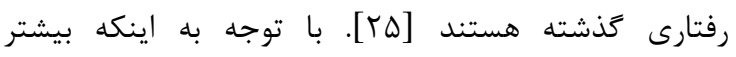

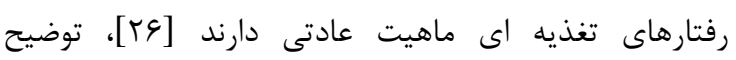
محدوديت سديم با رفتار كذشته قابل توجيه است فادئ دارند

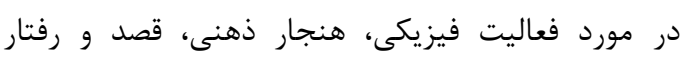

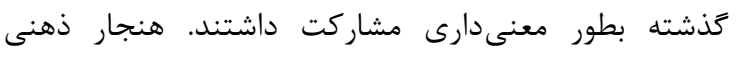

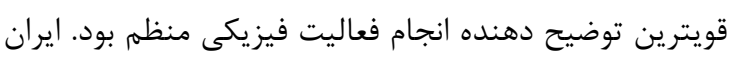

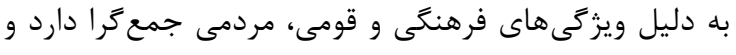

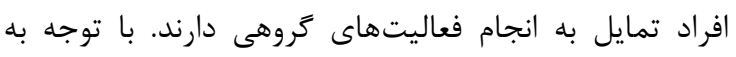

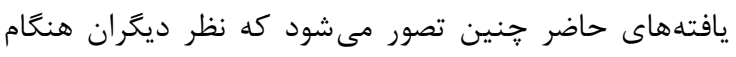

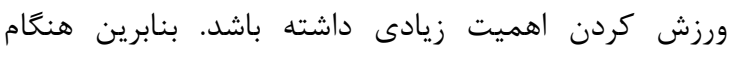

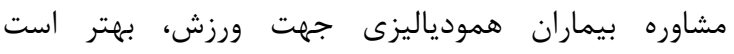

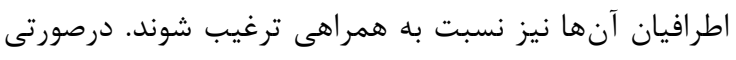

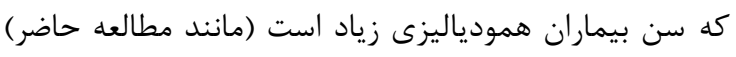

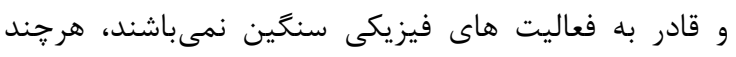

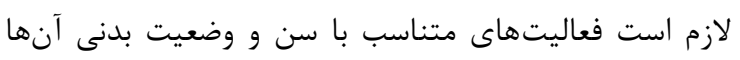

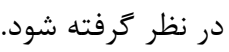

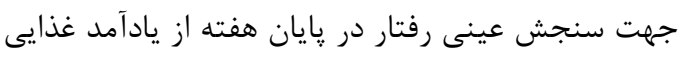

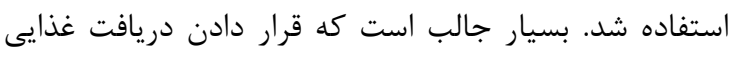

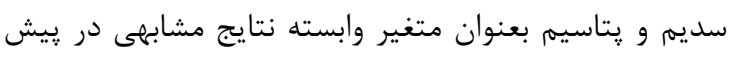

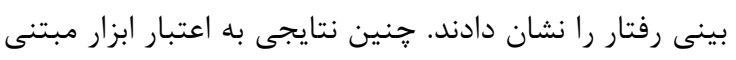

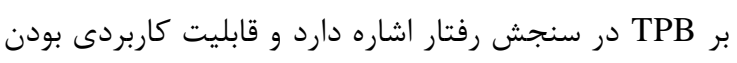

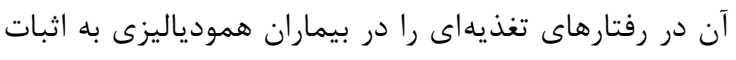

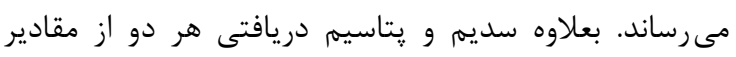

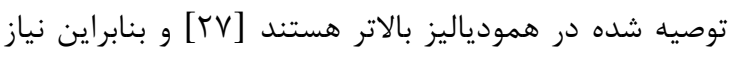

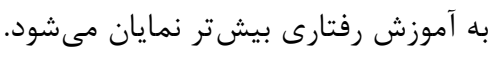

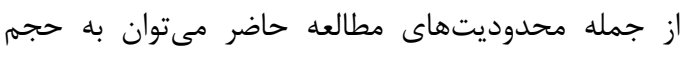

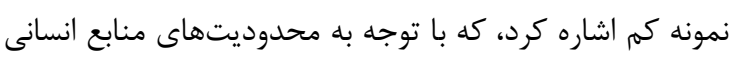

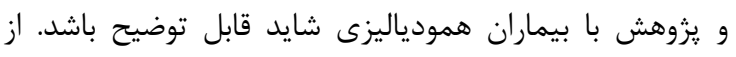

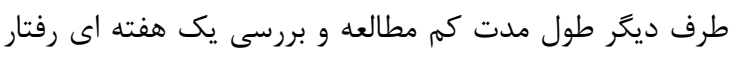

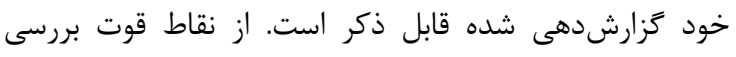

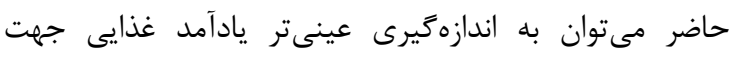
سنجش سديم و يتاسيم اشاره نمود. همجنين اندازه كيرى بانها
يتاسيم غذايى دريافت شده به عنوان متغير وابسته قرار

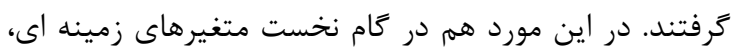

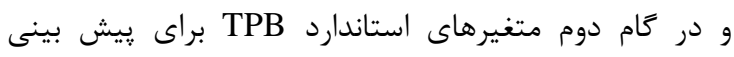

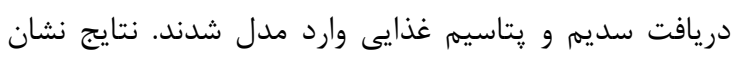

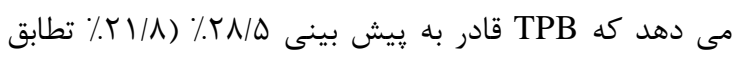

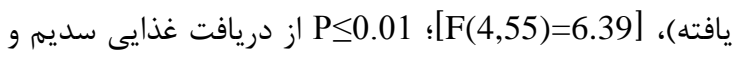

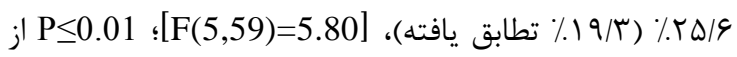

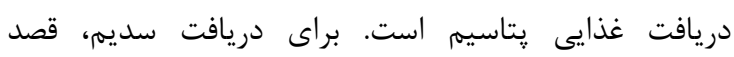

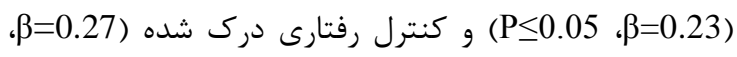

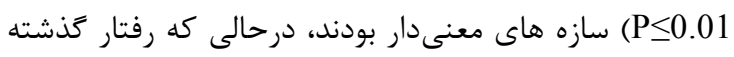
(P=0.19)،

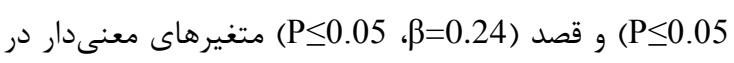

$$
\text { ييش بينى دريافت يتاسيم بودند. }
$$

در اين مطالعه قابليت تئورى TPB در پِيش بينى رفتار

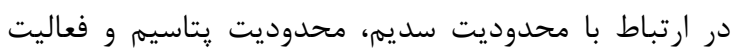

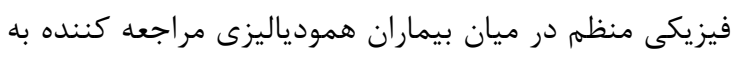

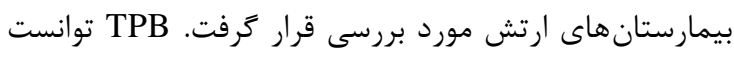

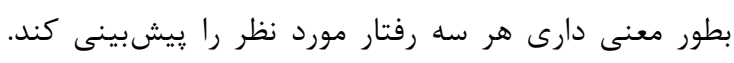

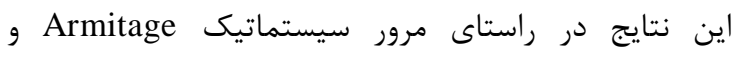
Cو Conner

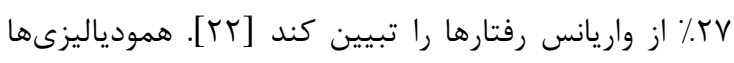

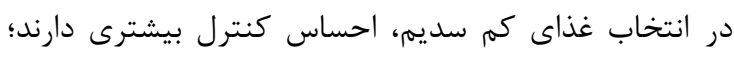

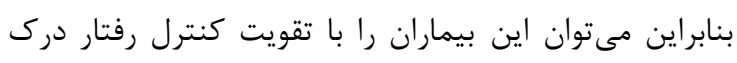

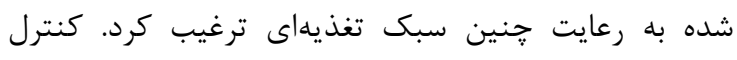

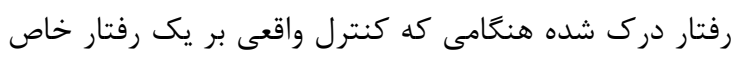

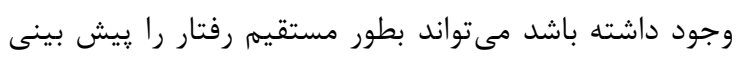

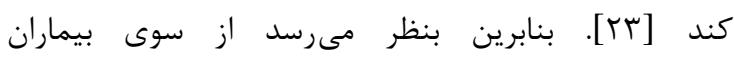

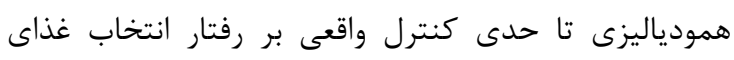

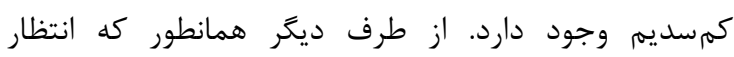

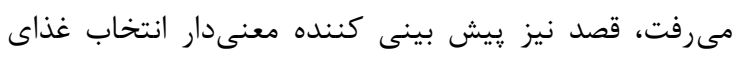

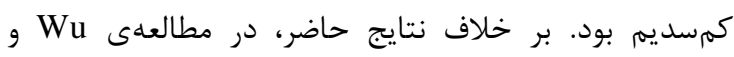

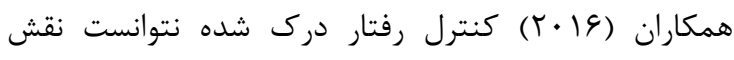

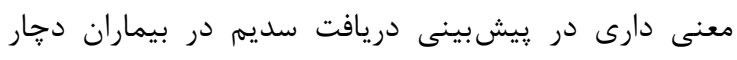

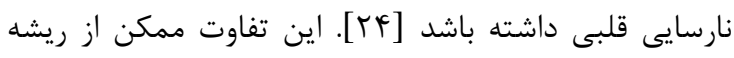

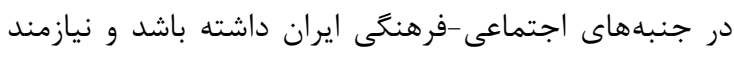
تحقيقات بيشتر است.

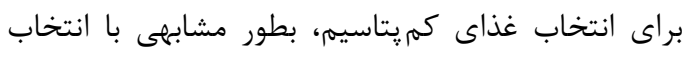

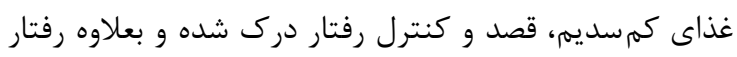

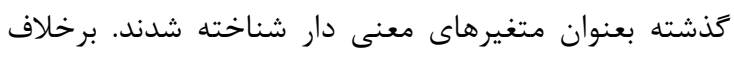

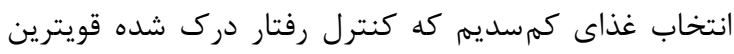

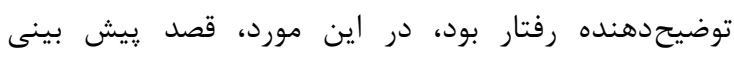
كنندكى بالاترى در توضيح انتخاب غذاى كمريتاسيم داشت. 
كيماران همودياليزى ارائه مى دهد و راه را براى انجام مداخلات

$$
\text { تشكر و قلروانى }
$$

نويسندكان از مجموعه دانشعاه علوم يزشكى آجا، كاركنان

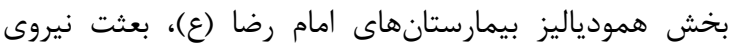

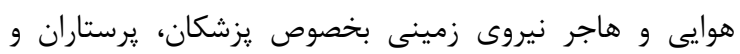

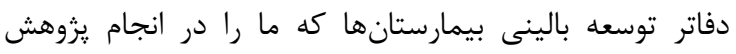

$$
\text { حاضر يارى نمودند تشكر مى كنند. }
$$

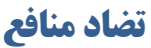

اين مطالعه براى نويسندًان هيجَّونه تضاد منافعى نداشته

\section{REFERENCES}

1. Himmelfarb J, MH S. Chronic kidney disease, dialysis, and transplantation : companion to Brenner \& Rector's the kidney. Philadelphia: Saunders/Elsevier; 2010.

2. Go AS, Chertow GM, Fan D, McCulloch CE, Hsu C-y. Chronic kidney disease and the risks of death, cardiovascular events, and hospitalization. New England Journal of Medicine. 2004;351(13):1296-305.

3. Matsushita $\mathrm{K}$, van der Velde M A, stor BC, Woodward M, Levey AS, de Jong PE, et al. Chronic Kidney Disease Prognosis Consortium. Association of estimated glomerular filtration rate and albuminuria with all-cause and cardiovascular mortality in general population cohorts: a collaborative meta-analysis. The Lancet. 2010;375 (9731):2073-81.

4. Jha V, Garcia-Garcia G, Iseki K, Li Z, Naicker S, Plattner B, et al. Chronic kidney disease: global dimension and perspectives. The Lancet. 2013;382(9888):260-72.

5. White SL, Chadban SJ, Jan S, Chapman JR, Cass A. How can we achieve global equity in provision of renal replacement therapy? Bulletin of the World Health Organization. 2008;86(3):229-37.

6. Boyer CB, Friend R, Chlouverakis G, Kaloyanides G. Social support and demographic factors influencing compliance of hemodialysis patients1. Journal of Applied Social Psychology. 1990;20(22):1902-18.

7. United States Renal Data System: Annual Data Report 2011 [Available from: https://www.usrds.org/adr.aspx Accessed: 2016.

8. Agarwal R, Nissenson AR, Batlle D, Coyne DW, Trout JR, Warnock DG. Prevalence, treatment, and control of hypertension in chronic hemodialysis patients in the United States. The American journal of medicine. 2003;115(4): 291-7.

9. Kayikcioglu M, Tumuklu M, Ozkahya M, Ozdogan O, Asci G, Duman S, et al. The benefit of salt restriction in the treatment of end-stage renal disease by haemodialysis. Nephrology Dialysis Transplantation. 2009;24(3):956-62.

10. Noori N, Kalantar-Zadeh K, Kovesdy CP, Murali SB, Bross R, Nissenson AR, et al. Dietary potassium intake and mortality in long-term hemodialysis patients. American journal of kidney diseases. 2010;56(2): 338-47.

11. De Moura Reboredo M, Henrique DMN, De Souza Faria R, Chaoubah A, Bastos MG, De Paula RB. Exercise training during hemodialysis reduces blood pressure and increases physical functioning and quality of life. Artificial organs. 2010;34(7):586-93.

12. Matsuzawa R, Matsunaga A, Wang G, Kutsuna T, Ishii A, Abe $\mathrm{Y}$, et al. Habitual physical activity measured by accelerometer and survival in maintenance hemodialysis patients. Clinical Journal of the American Society of

$$
\begin{aligned}
& \text { توسط افراد آموزش ديده و بصورت مصاحبه جهره به جهره } \\
& \text { انجام كرفته است. } \\
& \text { ييشنهاد مىشود تا مطالعه مشابه يِيامدهاى رفتارى را در } \\
& \text { در حجم نمونه بالاتر و مدت بيشترى دنبال كنند، همجنين از } \\
& \text { آزمايشهاى سديم و گتاسيمم سرمى (و ساير اندازه گيرىهاى } \\
& \text { تحت بالينى) در مدلهاى TPB بهره ببرند. } \\
& \text { نتيجه كَيرى } \\
& \text { مطالعه جارى قابليت TPB در ارتباط با سه رفتار مهرم در } \\
& \text { بيماران همودياليزى را محك زده است و راهكارهاى مفيدى } \\
& \text { در طراحى مداخلات آموزشى در اين بيماران را در اختيار } \\
& \text { مراقبين سلامت قرار مى دهد. يافتههاى مطالعه حاضر نتايج } \\
& \text { ارزشمندى در حمايت از تئورى رفتار برنامهريزى شده در }
\end{aligned}
$$

Nephrology. 2012;7(12):2010-6.

13. Ajzen I. The Theory of Planned Behavior. Organizational Behavior and Human Decision Processes. 1991;50(2): 179-211.

14. Kim K, Reicks M, Sjoberg S. Applying the theory of planned behavior to predict dairy product consumption by older adults. Journal of Nutrition Education and Behavior. 2003;35(6):294-301.

15. Kassem NO, Lee JW, Modeste NN, Johnston PK. Understanding soft drink consumption among female adolescents using the Theory of Planned Behavior. Health Education Research. 2003;18(3):278-91.

16. Rah JH, Hasler CM, Painter JE, Chapman-Novakofski KM. Applying the theory of planned behavior to women's behavioral attitudes on and consumption of soy products. Journal of Nutrition Education and Behavior. 2004; 36(5):238-44

17. Ronald P, Kerry C, Linda T, Nandini K, Ronald S. Aerobic physical activity and resistance training: an application of the theory of planned behavior among adults with type 2 diabetes in a random, national sample of Canadians. International Journal of Behavioral Nutrition and Physical Activity. 2008;5.

18. Fincham DS. Predicting Dietary and Fluid Adherence in Hemodialysis: An Application and Extension of the Theory of Planned Behaviour: University of Stellenbosch; 2005 .

19. Eng JJ, Martin Ginis KA. Using the theory of planned behavior to predict leisure time physical activity among people with chronic kidney disease. Rehabilitation Psychology. 2007;52(4):435.

20. George D, Mallery P. SPSS for Windows step by step: A simple guide and reference. 11.0 update. Allyn \& Bacon. Boston, USA. 2003.

21. Francis JJ, Eccles MP, Johnston M, Walker A, Grimshaw J, Foy $R$, et al. Constructing questionnaires based on the theory of planned behaviour. A manual for health services researchers. 2004;2010:2-12.

22. Armitage CJ, Conner M. Efficacy of the theory of planned behaviour: A meta-analytic review. British journal of social psychology. 2001;40(4):471-99.

23. Ajzen I, Madden TJ. Prediction of goal-directed behavior: Attitudes, intentions, and perceived behavioral control. Journal of experimental social psychology. 1986;22(5): 453-74.

24. Wu J-R, Lennie TA, Dunbar SB, Pressler SJ, Moser DK. Does the Theory of Planned Behavior Predict Dietary Sodium Intake in Patients With Heart Failure? Western Journal of Nursing Research. 2016:01939459166 72661.

25. Sutton S. The past predicts the future: Interpreting behaviour-behaviour relationships in social psychological 
models of health behaviour. 1994.

26. Kumanyika SK, Bowen D, Rolls BJ, Van Horn L, Perri MG,

Czajkowski SM, et al. Maintenance of dietary behavior change. Health Psychology. 2000;19(1S):42.
27. Mahan LK, Raymond JL. Krause's Food \& The Nutrition Care Process. 14th ed. St. Louis, Missouri: Elsevier; 2014. 